\title{
NOTAS SOBRE O ARGUMENTO DA LOUCURA NA PRIMEIRA MEDITAÇÃO
}

\author{
Ethel Menezes da Rocha**
}

\section{RESUMO}

O objetivo desse artigo é argumentar em favor da tese interpretativa segundo a qual nas Meditações Metafísicas Descartes, na Primeira Meditação, não recusa o argumento da loucura mas, ao contrário, utiliza-o em uma forma mais radical. Mais ainda, segundo a leitura a ser aqui defendida, o argumento da loucura em sua forma mais radical é absolutamente necessário para a eficácia da dúvida cartesiana. Através das hipóteses do sonho e do Deus Enganador, Descartes anula o aspecto individual, particular do argumento da loucura radicalizando-o. Ao admitir com essas hipóteses a possibilidade de todo homem fabricar seus próprios "dados sensíveis" e exercer a razão de modo incoerente, como o que ocorre com o louco, Descartes pode, ao final da Primeira Meditação, pôr em questão todo e qualquer critério de evidência.

Palavras-chave: Argumento da loucura. Hipótese do sonho. Hipótese do Deus Enganador.

\section{ABSTRACT}

The purpose of this article is to contend for the reading of the Meditations on First Philosophy according to which Descartes in the First Meditation does not reject madness as an argument but, indeed, uses it in an even more radical form. Furthermore, according to the reading here defended,

\footnotetext{
** Professora do Departamento de Filosofia da Universidade Federal do Rio de Janeiro(UFRJ).E-mail: ethel.rocha55@gmail.com
} 
the possibility of madness in its radical form is absolutely necessary for the efficacy of Cartesian doubt. Through the dream argument and the hypothesis of a Deceiving God, Descartes annuls the individual feature of madness, which allows him to appeal to a more radical version of it. Through these arguments, the possibility arises that, just like madmen, every man fabricates his own "sense data" and thinks incoherently, and this is what makes it possible for Descartes to question all criteria of evidence at the end of the First Meditation.

Keywords: Argument of madness. Dream hypothesis. Hypothesis of a Deceiving God.

O ponto de partida da presente análise é a tese interpretativa segundo a qual Descartes em sua Primeira Meditação das Meditações Metafísicas, ${ }^{1}$ ao pretender pôr em questão todo suposto conhecimento fornecido pelos sentidos, determina claramente o objetivo último do todo das Meditações, a saber, pôr em questão o modelo epistêmico de uma tradição escolástica de inspiração essencialmente aristotélica segundo a qual não há ideia no intelecto que não tenha antes passado pelos sentidos. Tendo esse pano de fundo em mente, o objetivo desse artigo é examinar uma pequena passagem da Primeira Meditação, em que Descartes, ao menos aparentemente, recusa um possível argumento, a saber, a hipótese da loucura, como razão relevante para duvidar do suposto conhecimento fornecido pelos sentidos. A possível recusa do assim posteriormente chamado "argumento cartesiano da loucura" foi alvo de intensa discussão entre Foucault e

\footnotetext{
${ }^{1}$ Sempre que possível as citações de passagens das Meditações Metafísicas serão extraídas da tradução de Bento Prado Junior; J. Guinburg (Coleção Pensadores, Ed. Victor Civita. Abril Cutural, São Paulo, 1973). Qualquer alteração será notificada. As citações serão acompanhadas da notação da edição em latim Adam \& Tannery (AT) da obra de Descartes seguida do número do volume e do número da página nessa edição.
} 
Derrida. ${ }^{2}$ Em poucas palavras, para Foucault, Descartes não só recusa o argumento da loucura nas Meditações, mas, para além disso, essa recusa é a expressão filosófica do que metaforicamente ele chama de uma decisão da era moderna de excluir o louco como o outro da razão e, portanto, o outro da civilização. Descartes nas Meditações estaria expressando na filosofia a decisão da era moderna de silenciar o louco, processo que, segundo ele, tem início com a fundação do Hospital Geral em 1656, isto é, com o que ele denomina de o Grande Internamento. Embora a questão política envolvida no tratamento negativo dedicado a certas minorias, como o louco e o leproso, seja de suma importância para outros fins, no que diz respeito à compreensão da argumentação filosófica cartesiana presente nas Meditações o exame dessa questão parece ser inteiramente dispensável e mesmo prejudicial a sua compreensão. Assim, na esteira da linha interpretativa de Derrida que rejeita a hipótese foucaultiana da recusa cartesiana da loucura na referida passagem das Meditações, a presente análise pretende mostrar que Descartes não só não recusa o argumento da loucura utilizando-se dele em uma forma mais radical, mas, além disso, que esse argumento é absolutamente necessário para a eficácia da dúvida cartesiana.

Até o momento em que aparece o que seria o argumento da loucura, a dúvida cartesiana se apoia em condições adversas externas ao sujeito percipiente: no fato das qualidades sensíveis das coisas particulares serem "pouco sensíveis" ou estarem mal localizadas, isto é, estarem "muito distantes". O argumento da loucura é a primeira tentativa de Descartes de constituir uma razão para duvidar que leva em consideração as condições internas ao sujeito que percebe. Essa tentativa, entretanto, apesar de

\footnotetext{
${ }^{2}$ Veja FOUCAULT, M. Folie et déraison: Histoire dela folie à l'âge classique. Paris: Plon, 1961.; My body, this paper, this fire. In: Oxford Literary Review. n. 1. 1979. v. 4. e DERRIDA, J. L'écriture et la difference. Paris: Édition du Seuil, 1967. Nesse artigo assumo, contra Foucault, que um texto filosófico pode ter seu sentido determinado por ele mesmo e o contexto filosófico em que se insere, independentemente do contexto político em que é escrito.
} 
satisfazer uma necessidade, a saber, a de considerar a possibilidade de encontrar-se obstáculos não externos, mas internos à própria percepção, apesar disso, por recorrer a obstáculos que são particulares e peculiares a alguns, não é suficiente como razão para duvidar dos sentidos como fonte de conhecimento, sendo suficiente para duvidar apenas da capacidade de alguns ao perceberem corretamente através dos sentidos. A hipótese a ser defendida aqui, então, é a de que por essa razão Descartes vê-se obrigado a universalizar o argumento da loucura, preservando seu aspecto relativo às condições internas do sujeito da percepção, abandonando, entretanto, o que há de idiossincrático nele. É precisamente porque Descartes pode pensar em uma possível disfunção interna ao agente cognoscente, a saber, uma obstrução natural em sua capacidade de recepção de dados sensíveis e em sua capacidade de exercer coerentemente a razão, como o que ocorre nos casos de loucura, que é possível estender a dúvida a todo pretenso conhecimento. Assim, será mostrado que para a eficácia da argumentação cartesiana, que pretende pôr em questão todo suposto conhecimento originado nos dados dos sentidos, ou em imagens sensíveis, esta possibilidade de disfunção interna presente idiossincraticamente no louco deve ser universalizada a ponto de poder ser possível pensar que ela se aplica a todo homem, constituindo assim sua própria natureza.

Tendo em um primeiro momento da dúvida introduzido razões para pôr em questão o que é fornecido pelos sentidos, no que concerne às percepções de coisas tênues e distantes, Descartes conclui que ao menos um tipo de percepção obtido diretamente dos sentidos escapa a essa dúvida, a saber, a suposta percepção da existência atual das coisas e situações particulares. Isto é, em um primeiro momento Descartes oferece razões para duvidar da veracidade das percepções das qualidades sensíveis das coisas singulares, recorrendo a condições externas ao agente cognoscente: essas coisas, cujo conhecimento sensível duvidamos, envolvem condições desfavoráveis a esse tipo de percepção: ou bem são pouco sensíveis de modo a mal afetarem nossos sentidos, ou bem estão 
mal localizadas de tal modo que sua percepção fica prejudicada. Apesar disso, afirma Descartes, outras coisas supostamente conhecidas pelos sentidos escapam ainda da dúvida: a primeira delas é a presença atual das coisas e situações singulares, exatamente tais como as experimentamos, a outra é a simples presença atual de coisas materiais, ainda que não exatamente como as experimentamos. Sendo assim, o passo seguinte de Descartes será examinar as condições internas ao agente cognoscente na busca de razões para pôr em questão o que escapara da dúvida até agora. $\mathrm{O}$ argumento da loucura aparece então como a primeira alternativa para pensar-se as condições internas do sujeito da percepção como desfavoráveis à percepção das coisas.

Tendo já posto em questão a possibilidade das qualidades sensíveis serem apreendidas diretamente pelos sentidos, Descartes passa a investigar o que mais é supostamente conhecido diretamente pelos sentidos, concluindo que "encontramos talvez muitas outras [coisas], das quais não se pode razoavelmente duvidar, embora as conhecêssemos por intermédio deles [os sentidos]: por exemplo, que eu esteja aqui, sentado junto ao fogo, vestido com um chambre, tendo este papel entre as mãos e coisas semelhantes". ${ }^{3}$ A menção bem como a, ao menos aparente, recusa do recurso ao argumento da loucura para rejeitar o suposto conhecimento da verdade aparece logo a seguir em um pequeno trecho da Primeira Meditação em que Descartes afirma:

E como poderia eu negar que estas mãos este corpo sejam meus? A não ser, talvez, que eu me compare a não sei quais insensatos, cujo cérebro está de tal modo ofuscado pelos negros vapores da bílis que constantemente asseguram que são reis quando são muito pobres; que estão vestidos de ouro e de púrpura quando estão inteiramente nus; ou imaginam ser cântaros ou ter um corpo de

\footnotetext{
${ }^{3}$ AT VII: 18. Tradução brasileira alterada: nessa passagem, no lugar de "coisas semelhantes", como consta no original em latim, na tradução brasileira e na francesa lê-se "coisas dessa natureza".
} 
vidro. Mas quê? São loucos e eu não seria menos extravagante se me guiasse por seus exemplos. ${ }^{4}$

O primeiro ponto a ser ressaltado é a caracterização da loucura nessa passagem das Meditações através de dois aspectos relacionados a uma disfunção interna do pensamento do sujeito da percepção: 1) o louco fabrica seus próprios “dados sensíveis" e 2) o louco é incapaz de operar corretamente a partir do que supostamente é dado a seus sentidos. Seu cérebro, "ofuscado pelos negros vapores da bílis" gera "dados sensíveis" e o torna incapaz de receber e articular o que supostamente o afeta: pensam estar vestidos de ouro quando estão inteiramente nus, imaginam ser cântaros ou ter corpo de vidro quando não o são. A loucura é caracterizada, portanto, como a disponibilidade mental não só de fabricar, gerar o que aparece como dado sensível, mas também a de prejudicar o exercício mesmo da razão. O recurso à possibilidade de se estar louco seria, então, suficiente para introduzir a possibilidade de condições desfavoráveis internas ao sujeito da percepção e, assim, pôr em questão a possibilidade do conhecimento, não fosse o caráter particular, individual da loucura. As disfunções nas capacidades de perceber e de articular supostos dados sensíveis são consideradas como características de percepções idiossincráticas. O louco é insensato e extravagante. Como veremos, através da hipótese do sonho e do Deus Enganador, Descartes pretenderá abolir o aspecto idiossincrático da loucura considerando a possibilidade de uma disfunção idêntica à da loucura, porém natural a todos os homens, preservando então o aspecto de uma possível disfunção interna ao sujeito da percepção.

No final da passagem dedicada ao que seria o argumento da loucura Descartes afirma: "Mas quê? São loucos e eu não seria menos extravagante se me guiasse por seus exemplos", o que a muitos (inclusive Foucault) sugere uma recusa por parte de Descartes ao recurso à

${ }^{4}$ AT VII: 19. 
possibilidade da loucura. E logo na frase imediatamente seguinte afirma: "Todavia, devo aqui considerar que sou homem e, por conseguinte, que tenho o costume de dormir e de representar, em meus sonhos as mesmas coisas, ou algumas menos verossímeis, que esses insensatos em vigília". O fato de Descartes imediatamente após o que seria sua rejeição do argumento da loucura introduzir a hipótese do sonho é muitas vezes considerado como uma confirmação de sua recusa do argumento da loucura. Entretanto, ao atentarmos para o que diz Descartes nessa passagem sobre o sonho, percebe-se que Descartes não descarta a possibilidade de algo idêntico ao que acontece nos sonhos ocorrer àquele que sonha. Ele diz ter o costume de em sonhos representar as mesmas coisas que esses insensatos. Mais ainda, como veremos a seguir, prosseguindo no texto, Descartes introduzirá uma caracterização do sonho muito semelhante à caracterização da loucura, que é justamente o que permitirá interpretarmos a hipótese do sonho como uma retomada do conteúdo do argumento da loucura. Por ora, gostaríamos, entretanto, de examinar em que medida a hipótese do sonho indica uma superação do argumento da loucura, isto é, precisar o que da hipótese da loucura é deixado de lado com a introdução da hipótese do sonho.

Uma pista do que deve ser compreendido com a oposição introduzida por Descartes entre loucura e sonho é o fato desta oposição ser introduzida chamando atenção para o fato de que, ao contrário do que faz o louco (extravagante), o que se faz nos sonhos é o costumeiro. A oposição é introduzida com as seguintes palavras "Todavia devo considerar que sou homem e, por conseguinte, que tenho o costume de dormir e de representar em meus sonhos...". ${ }^{5}$ A oposição parece ser, portanto, entre o comportamento de alguns homens, "loucos" e "extravagantes" da frase anterior, e o costume de todos os homens. Em oposição a representações idiossincráticas, Descartes introduz as representações de todos os homens, a saber, as representações durante

${ }^{5}$ AT VII: 19.6 
o sonho, estado que todos os homens experimentam habitualmente. $\mathrm{O}$ que determina que os loucos são insensatos, extravagantes, é o fato de perceberem-se como vestidos quando os outros os percebem como estando nus, ou de perceberem-se como cântaros ou como tendo corpos de vidro, quando os outros os percebem como homens constituídos de carne e osso, etc. Uma das caracterizações do louco, portanto, nessa passagem da Primeira Meditação, é como aquele cujas percepções sensíveis são fabricadas por ele de modo peculiar, ao invés de serem produzidas pela afecção dos dados sensíveis, como ocorreria com todos os outros, que seriam aqueles que percebem as coisas. Sendo assim, ao opor a loucura ao sonho, Descartes parece pretender recusar apenas parcialmente a hipótese da loucura, rejeitando apenas um aspecto, a saber, a idiossincrasia do louco. Descartes rejeita de imediato o aspecto pessoal, individual do argumento da loucura, na medida em que desse modo não seria possível duvidar dos sentidos como fonte de conhecimento, mas apenas da capacidade de alguns perceberem corretamente através dos sentidos. Além de idiossincrático, entretanto, a caracterização do louco envolve um outro aspecto, a saber, que ele tem percepções sensíveis diferentes das percepções daquele que considera a percepção sensível como um bom critério para determinar-se a verdade. É esse aspecto que será, logo em seguida, retomado na hipótese do sonho. Eliminada a idiossincrasia do louco não foi eliminada, portanto, a possibilidade de todo o homem representar o mundo como os loucos.

Como se percebe pelo trecho dedicado à hipótese do sonho, Descartes ao expor como as representações se dão nos sonhos, como ele próprio havia advertido anteriormente, menciona representações muito semelhantes às apresentadas no caso da loucura, em que o louco aparece como aquele que se vê vestido de ouro quando está nu, o que confirma a leitura de que a hipótese da loucura é retomada aqui, abstração feita de seu caráter individual. Nas palavras de Descartes:

Quantas vezes ocorreu-me sonhar, durante a noite, que estava vestido, que estava junto ao fogo, embora estivesse inteiramente nu 
dentro de meu leito? Parece-me agora que não é com olhos adormecidos que contemplo este papel; que esta cabeça que eu mexo não está dormente.

Entretanto, prossegue Descartes, "vejo tão manifestamente que não há quaisquer indícios concludentes, nem marcas assaz certas por onde se possa distinguir nitidamente a vigília do sono". ${ }^{6}$ Descartes, portanto, começa a introduzir a possibilidade de que os sentidos não sejam, para os homens, fonte segura de conhecimento das coisas das quais pretende ser fonte de conhecimento: pode ser que ao se perceber sensivelmente algo (a existência das coisas singulares, por exemplo, ou como essas coisas são), na verdade dormimos e sonhamos. As representações nos sonhos, entretanto, não são produzidas a partir de dados sensíveis, mas fabricadas por aquele que sonha de tal forma que são idênticas às que supostamente recebemos pelos sentidos. Exatamente porque nos sonhos fabricamos representações idênticas às representações supostamente advindas dos sentidos, não temos meios de distingui-las. É possível, pois, que todas as representações que nos parecem advir dos sentidos sejam fabricadas como as que são fabricadas nos sonhos e na loucura. Até aqui Descartes teria mostrado que nossas representações em vigília podem ser como nos sonhos, e que nos sonhos fabricamos representações como as que supostamente são fornecidas pelos sentidos; não mostrou, entretanto, por que o fato de fabricarmos essas representações nos sonhos e, consequentemente, por que a semelhança entre essas representações e nossas representações em vigília tornaria as representações em vigília não confiáveis. O que há com as representações nos sonhos que as torna não uma previsão, ou uma visão mais clara da realidade, mas ao contrário, uma fabricação ilegítima desta, como o que ocorre com os loucos?

Imediatamente a seguir Descartes introduz uma analogia entre as representações que temos em sonho e os quadros ou pinturas. Um dos

${ }^{6}$ AT VII: 19.7 
objetivos dessa analogia é mostrar por que as representações nos sonhos não são confiáveis e assim responder à questão de por que a impossibilidade de distinção entre o que seriam ideias sensíveis e ideias da imaginação torna não confiáveis as ideias supostamente advindas dos sentidos e as ideias nos sonhos. Através dessa analogia, Descartes ressalta a possibilidade de que as ideias por nós compostas na imaginação sejam arbitrariamente inventadas como os quadros dos pintores e, nesse sentido, não serem confiáveis como fonte de conhecimento. Ao comparar nossas ideias nos sonhos que não são fornecidas pelos sentidos, mas sim pela imaginação, como os quadros pintados a partir da imaginação dos pintores, Descartes admite a possibilidade de que a "imaginação [seja] assaz extravagante para inventar algo de tão novo, que jamais tenhamos visto coisa semelhante e que assim sua obra nos represente uma coisa puramente fictícia e absolutamente falsa". ${ }^{7}$ Isto é, Descartes admite a possibilidade da imaginação operar de modo arbitrário e extravagante, como ocorre no caso da loucura, ao compor ideias. E se a ideias nos sonhos são ideias da imaginação e se assemelham ao que seriam ideias dos sentidos, então estas que nos aparecem como ideias dos sentidos podem ser simplesmente produções arbitrárias de nossa imaginação. É possível, pois, que todas as representações que nos parecem advir dos sentidos sejam fabricadas como as que são fabricadas nos sonhos e na loucura.

Assim, a primeira consequência envolvida na analogia entre nossas ideias imaginárias nos sonhos e as imagens nos quadros de pintores permite compreender a primeira radicalização da hipótese da loucura: porque sonhamos formamos ideias imaginárias que, entretanto, podem ser arbitrariamente compostas, o que as desqualifica como fontes de conhecimento. E porque não podemos distinguir nossas ideias supostamente advindas dos sentidos e as ideias dos sonhos, essas nossas ideias supostamente advindas dos sentidos podem ser meras fabricações arbitrárias de nossa mente. Desse modo, como ocorre com os loucos, pode ser que nossas ideias

\footnotetext{
${ }^{7}$ AT VII: 20.8
} 
supostamente dos sentidos sejam geradas arbitrariamente, e, diferentemente do caso da loucura, entretanto, essa possível fabricação arbitrária não ocorreria apenas em alguns, mas em todos os homens.

Com a hipótese do sonho e a tematização da imaginação através da analogia entre ideias e quadros, Descartes introduz então uma primeira possível disfunção interna ao sujeito da percepção mostrando a possibilidade deste gerar seus próprios conteúdos representativos como se estes, entretanto, fossem advindos do mundo externo através da afecção dos sentidos. Se não é possível, com base nas percepções sensíveis, distinguir o sonho da vigília, então na vigília pode ocorrer exatamente como nos sonhos: geramos por nós mesmos, sem auxílio direto de qualquer coisa externa a nós, os conteúdos de nossas percepções supostamente sensíveis. É nesse sentido que é plausível a leitura segundo a qual a hipótese do sonho, que visa pôr em questão as ideias supostamente recebidas diretamente dos sentidos, é a primeira etapa da radicalização do argumento da loucura presente nas Meditações: através dessa hipótese Descartes introduz a possibilidade não de que alguns homens (aqueles cujo cérebro foi invadido pelos vapores da bílis), mas de que todos os homens fabriquem suas próprias percepções sensíveis e, consequentemente, introduz a possibilidade de que o que aparece aos homens como dados sensíveis seja nada além de invenção de suas mentes.

Há ainda outra conseqüência, dessa analogia entre ideias e quadros, importante para a leitura segundo a qual Descartes retoma, radicalizando, a hipótese da loucura. Após introduzir a possibilidade da arbitrariedade das ideias compostas pela imaginação, Descartes explica o que escapa a essa possibilidade com as seguintes palavras:

ainda que essas coisas gerais [...] possam ser imaginárias é preciso, todavia, confessar que há coisas ainda mais simples e mais universais que são verdadeiras e existentes; de cuja mistura [...] são formadas todas essas imagens das coisas que residem em nosso pensamento. ${ }^{8}$

${ }^{8}$ AT VII: 20. 
Prosseguindo no texto, percebemos que o simples de que se trata aqui são as ideias que são condições de possibilidade das ideias da imaginação e dos sentidos. Nas palavras de Descartes: “... Desse gênero de coisas é a natureza corpórea em geral, e sua extensão; juntamente com a figura das coisas extensas, sua quantidade, ou grandeza, e seu número; como também o lugar em que estão, os tempos que mede sua duração e coisas semelhantes." Descartes acrescenta, então, a essa lista das coisas que escaparam da razão de duvidar introduzida pela hipótese do sonho conjugada à analogia entre ideias e quadros, a Aritmética e a Geometria, naquilo que elas têm de simples. Emsuas palavras, "a Aritmética, a Geometria e as outras ciências desta natureza, que não tratam senão de coisas muito simplese muito gerais $[. .$.$] contêm alguma coisa de certo e indubitável". { }^{9}$

Os termos utilizados por Descartes logo a seguir, ao introduzir a dúvida do Deus Enganador, deixam claro que o simples consiste nas ideias que são condições de possibilidade de qualquer ideia de corpo e nas operações da razão exemplificadas por operações da matemática. Em seus termos: "Ora, quem pode assegurar que esse Deus não tenha feito com que não haja nenhuma terra, nenhum céu, nenhum corpo extenso, nenhuma figura, nenhuma grandeza, nenhum lugar e que, não obstante, eu tenha o sentimento de todas essas coisas". Isto é, quem pode assegurar que Deus não tenha feito com que eu me engane não apenas com relação às minhas percepções sensíveis atuais, mas mesmo com relação a qualquer ideia que eu possa ter ou vir a ter do mundo físico. "E", prossegue Descartes, "mesmo, [...] que eu me engane todas as vezes em que faço $a$ adição de dois mais três, ou em que enumero os lados de um quadrado, ou em que julgo alguma coisa ainda mais fácil" ${ }^{10}$ Ou seja, e tenha feito com que eu me engane mesmo com relação às minhas operações racionais mais simples, das quais as operações matemáticas são exemplos.

Essa segunda consequência envolvida na analogia introduzida por

\footnotetext{
${ }^{9}$ AT VII: 20.

${ }^{10}$ AT VII: 21. (Grifo nosso).
} 
Descartes entre ideias e quadros nos parece relevante para o segundo aspecto da radicalização do argumento da loucura, porque é o que permitirá que Descartes complete seu questionamento acerca de quaisquer critérios de evidência. Pela analogia Descartes mostra que há ainda algum critério de evidência confiável, a saber, a percepção do simples e as operações racionais simples, e através da hipótese do Deus enganador Descartes põe em questão todo e qualquer critério de evidência. Ao pôr em questão qualquer critério de evidência, Descartes iguala o sujeito da percepção aos loucos na medida em que os critérios de evidência deste último estão sempre em questão. Se é possível que Deus sistematicamente engane o sujeito percipiente, então é possível que todo sujeito de percepção tenha a mesma disfunção que o louco. É possível que se esteja sistematicamente enganado na medida em que pode não existir "nenhuma terra, nenhum céu, nenhum corpo extenso" (e não apenas essa terra, esse céu que penso perceber atualmente) "mesmo que eu tenha o sentimento de todas essas coisas" e na medida em que posso me enganar "todas as vezes em que faço a adição de dois mais três, ou em que enumero os lados de um quadrado [...] ou em que julgo alguma coisa ainda mais fácil". Mas se é assim, como os loucos, é possível que as operações cognitivas da minha razão não operem coerentemente ou corretamente .

Se a análise acima apresentada é plausível, é então plausível também afirmar que na Primeira Meditação Descartes precisa do argumento da loucura para pôr em questão todo e qualquer critério de evidência, já que isso só é possível admitindo-se uma disfunção interna ao sujeito da percepção, como ocorre com os loucos. Através da hipótese do sonho, da arbitrariedade da imaginação e do Deus enganador Descartes retoma o argumento da loucura mostrando ser possível que o sujeito da percepção fabrique seus próprios "dados sensíveis", fabrique arbitrariamente suas idéias sobre o mundo e pense incoerentemente. Mas, na medida em que o sonho, a imaginação e o possível Deus Enganador ocorrem a todo homem, ao retomar o argumento da loucura Descartes o radicaliza abandonando seu caráter individual, pessoal. 
116 Educação e Filosofia Uberlândia, v. 25, N. Especial, p. 103-116, 2011 - ISSN 0102-6801

\section{REFERÊNCIAS}

DERRIDA, J. L'écriture et la difference. Paris: Édition du Seuil, 1967.

DESCARTES, R. Oeuvres de Descartes, Edição de Por Charles Adam e Paul Tannery. Paris: Libraire Philosophique J. Vrin, 1973-1982.

FOUCAULT, M. Folie et déraison: Histoire dela folie à l'âge classique. Paris: Plon, 1961.

. My body, this paper, this fire. In: Oxford Literay Review. n. 1. 1979. v. 4.

Data de registro: $18 / 07 / 2011$ Data de aceite: $24 / 08 / 2011$ 